\title{
RELATIONSHIP OF THE LONG THORACIC NERVE TO THE SCAPULAR TIP: AN AID TO PREVENTION OF PROXIMAL NERVE INJURY
}

Jorge D. Salazar, MD

John R. Doty, MD

Elaine E. Tseng, MD

Philip C. Marin, MD

John A. Girotto, MD

Glen S. Roseborough, MD

Stephen C. Yang, MD

Richard F. Heitmiller, MD
Objective: The objective was to determine the course of the long thoracic nerve relative to the scapula as an aid to the prevention of proximal long thoracic nerve injuries. Methods: Eighteen fresh cadavers (7 male, 11 female) were studied. Each was sequentially placed in the transaxillary and posterolateral thoracotomy positions, and the distance of the long thoracic nerve from the scapular tip and anterior scapular border was measured. The measurements were made bilaterally; the mean, standard deviation, and $99 \%$ confidence interval were calculated for each position by gender. Results: Distances from the scapular tip to the long thoracic nerve are listed as mean/outer range: transaxillary thoracotomy, male 4.9/7.0 cm left, $5.2 / 7.5 \mathrm{~cm}$ right; female $4.3 / 5.0 \mathrm{~cm}$ left, $4.7 / 6.0$ cm right; posterolateral thoracotomy, male $3.1 / 6.0 \mathrm{~cm}$ left, $4.5 / 5.1 \mathrm{~cm}$ right; female $3.2 / 4.5 \mathrm{~cm}$ left, $3.8 / 5.5 \mathrm{~cm}$ right. In all instances, the long thoracic nerve was furthest from the scapula at its tip. Conclusion: For patients positioned for a transaxillary thoracotomy, incision sites should be at least 7.5 and $6.0 \mathrm{~cm}$ anterior to the scapular tip for male and female patients, respectively. For patients in posterolateral thoracotomy positioning, incisions should be 6.0 and $5.5 \mathrm{~cm}$ anterior to the scapular tip for male and female patients, respectively. By using these anatomic guidelines, we believe that the incidence of iatrogenic proximal long thoracic nerve injury can be minimized. (J Thorac Cardiovasc Surg 1998;116:960-4)
$\mathrm{D}$ enervation of the serratus anterior muscle from proximal long thoracic nerve (LTN) injury results in loss of scapular tip stabilization, or "winged scapula." This injury results in prolonged disability for the patient, ${ }^{1,2}$ and potential medicolegal concerns for the physician. For thoracic surgeons, the LTN is at risk for proximal injury during transaxillary thoracotomy, 3,4 video-thoracoscopy port insertion, first rib resection, and chest tube placement. The purpose of this study was to map the course of the LTN relative to the scapular tip and the anterior scapular border, thereby developing

From the Department of Surgery, Division of Thoracic Surgery, The Johns Hopkins Medical Institutions, Baltimore, Md.

Received for publication March 19, 1998; revisions requested May 13, 1998; revisions received Aug 25, 1998; accepted for publication Aug 28, 1998.

This work was supported by the Evelyn Glick Fund for Thoracic Surgery.

Address for reprints: Richard F. Heitmiller, MD, Osler 624, Johns Hopkins Hospital, Baltimore, MD 21287-5674.

Copyright $@ 1998$ by Mosby, Inc.

0022-5223/98 $\$ 5.00+0 \quad \mathbf{1 2 / 1 / 9 4 2 2 9}$ guidelines to aid in the prevention of proximal LTN injuries.

\section{Patients and methods}

Eighteen fresh adult cadavers provided by the Maryland State Anatomy Board were studied, of which 7 were male and 11 were female. Each cadaver was placed in the lateral decubitus position without table flexion, and the ipsilateral elbow flexed and the arm extended overhead to simulate positioning for a standard transaxillary incision. A vertical skin incision was made in the posterior axillary line. The dissection was carried down to the medial edge of the latissimus dorsi muscle, which was retracted posteriorly to expose the serratus anterior muscle. The LTN was identified on the surface of the serratus anterior muscle. The scapular tip and anterior scapular border were identified but not skeletonized, thus preserving normal anatomic relationships. The distance from the scapular tip to the LTN was measured and recorded (Fig 1). Additional measurements were made and recorded from the LTN to the anterior scapular border cephalad to the scapular tip at 2-cm intervals. The ipsilateral arm was then extended forward, as for standard posterolateral thoracotomy positioning. This rotated the scapula anteriorly closer to the LTN, which remained in a fixed position on the chest wall. 

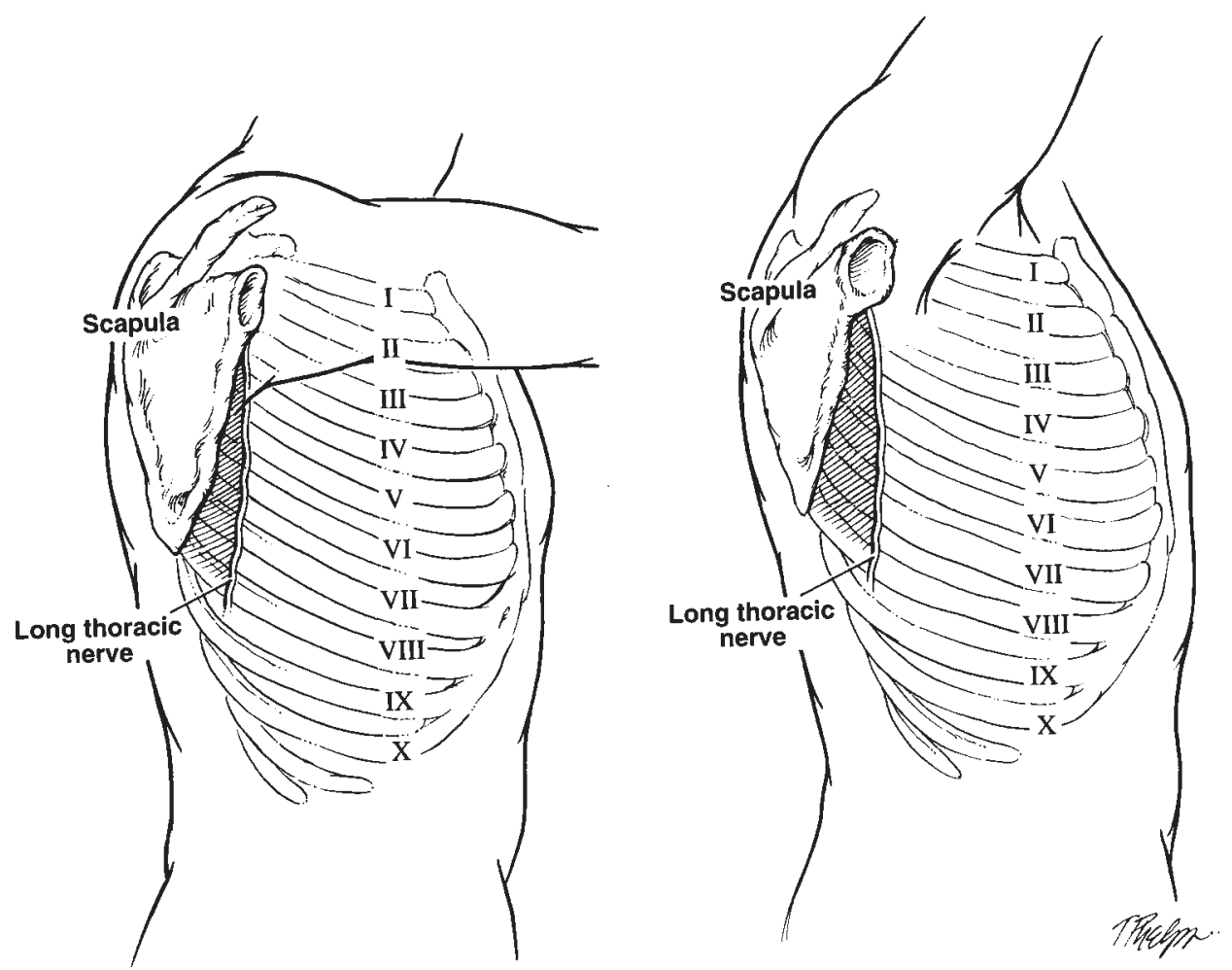

Fig l. Each cadaver was placed in the lateral decubitus position with the ipsilateral arm positioned as for a posterolateral thoracotomy (left) and transaxillary thoracotomy (right). The ribs are labeled, and the distance from the anterior scapular border to the LTN is shaded.

The same measurements were repeated and recorded. Transaxillary and posteroloateral thoracotomy positioning measurements were performed bilaterally on all cadavers, except one male right axilla and one female left axilla, which were excluded because of a previous operation.

All measurements were tabulated; then the mean, standard deviation, and $99 \%$ confidence intervals for each position were calculated.

\section{Results}

Thirty-four axillae from 18 fresh cadavers underwent dissection and measurements. Table I displays the results for transaxillary thoracotomy positioning. The mean distance, standard deviation, upper bound of the 99\% confidence interval, and outer value of the range of measurements were recorded. All distances are in centimeters and reflect the distance measured transversely from the anterior scapular border to the LTN. Measurements were made from the scapular "tip" and at $2 \mathrm{~cm}$ intervals along the anterior scapular border cephalad from the scapular tip. The data are presented by gender and side. For male cadavers in the transaxillary thoracotomy position, the left LTN courses a mean dis- tance of $4.9 \mathrm{~cm}$ (range, $3.2-7.0 \mathrm{~cm}$ ) anterior to the left scapular tip; the right LTN courses a mean distance of $5.2 \mathrm{~cm}$ (range, $3.7-7.5 \mathrm{~cm}$ ) anterior to the right scapular tip. For female cadavers in the transaxillary thoracotomy position, the left LTN courses a mean distance of 4.3 $\mathrm{cm}$ (range, 3.0-5.0 cm) anterior to the left scapular tip; the right LTN courses a mean distance of $4.7 \mathrm{~cm}$ (range, $3.0-6.0 \mathrm{~cm}$ ) anterior to the right scapular tip.

Table II displays the results for posterolateral thoracotomy positioning. For male cadavers in the posterolateral thoracotomy position, the left LTN courses a mean distance of $3.1 \mathrm{~cm}$ (range, 1.5-6.0 cm) anterior to the left scapular tip; the right LTN courses a mean distance of $4.5 \mathrm{~cm}$ (range, $3.5-5.1 \mathrm{~cm}$ ) anterior to the right scapular tip. For female cadavers in the posterolateral thoracotomy position, the left LTN courses a mean distance of 3.2 $\mathrm{cm}$ (range, 2.0-4.5 cm) anterior to the left scapular tip; the right LTN courses a mean distance of $3.8 \mathrm{~cm}$ (range, $2.0-5.5 \mathrm{~cm}$ ) anterior to the right scapular tip.

\section{Discussion}

Loss of scapular tip fixation results in shoulder destabilization, which has been referred to as alar scapula 


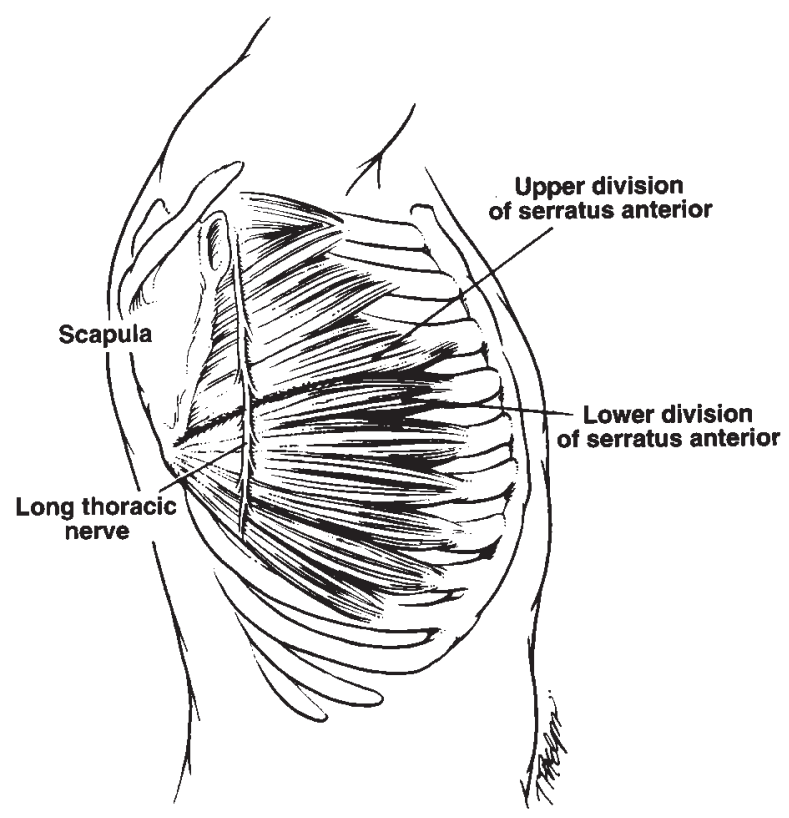

Fig 2. The serratus anterior is anatomically divided into 2 components, an upper division in which the muscular slips insert individually onto the scapula and a lower division, the muscular slips of which converge posteriorly in a tendon that inserts to the scapular tip.

Table I. Transaxillary thoracotomy positioning

\begin{tabular}{|c|c|c|c|c|c|c|c|c|}
\hline & \multicolumn{4}{|c|}{ Left } & \multicolumn{4}{|c|}{ Right } \\
\hline & "Tip" & 2 & 4 & 6 & "Tip" & 2 & 4 & 6 \\
\hline \multicolumn{9}{|l|}{ Male } \\
\hline Mean & 4.9 & 4.0 & 3.5 & 3.3 & 5.2 & 4.4 & 4.1 & 3.2 \\
\hline SD & 1.2 & 0.8 & 0.9 & 0.7 & 1.3 & 1.1 & 1.1 & 1.5 \\
\hline $99 \%$ CI & 6.0 & 4.9 & 4.4 & 4.0 & 6.4 & 5.5 & 5.1 & 4.7 \\
\hline Outer range & 7.0 & 5.0 & 5.0 & 4.2 & 7.5 & 6.0 & 6.0 & 6.0 \\
\hline \multicolumn{9}{|l|}{ Female } \\
\hline Mean & 4.3 & 3.5 & 3.1 & 2.8 & 4.7 & 4.0 & 3.3 & 2.7 \\
\hline SD & 0.7 & 0.8 & 0.7 & 0.6 & 1.0 & 1.0 & 1.1 & 1.4 \\
\hline $99 \%$ CI & 4.9 & 4.1 & 3.6 & 3.3 & 5.4 & 4.8 & 4.2 & 3.8 \\
\hline Outer range & 5.0 & 5.0 & 4.0 & 3.5 & 6.0 & 5.5 & 4.5 & 4.0 \\
\hline
\end{tabular}

All distances are in centimeters and reflect the distance measured transversely from the anterior scapular border to the LTN. Measurements were made at the scapular "tip" and at 2-cm intervals along the anterior scapular border cephalad from the scapular tip. $S D$, Standard deviation; $99 \% C I$, upper bound of the $99 \%$ confidence interval for the mean; outer range, outer value of the range of measurements.

or winged scapula. Winged scapula may result from either traumatic disruption of the serratus anterior muscle at its scapular insertion site or paralysis of the serratus anterior muscle as the result of LTN injury. After an extensive literature review, Prescott and Zollinger ${ }^{5}$ concluded that winged scapula is most commonly a
Table II. Posterolateral thoracotomy positioning

\begin{tabular}{|c|c|c|c|c|c|c|c|c|}
\hline & \multicolumn{4}{|c|}{ Left } & \multicolumn{4}{|c|}{ Right } \\
\hline & "Tip" & 2 & 4 & 6 & “Tip" & 2 & 4 & 6 \\
\hline \multicolumn{9}{|l|}{ Male } \\
\hline Mean & 3.1 & 2.6 & 2.4 & 2.4 & 4.5 & 3.5 & 3.1 & 2.5 \\
\hline SD & 1.6 & 1.2 & 1.2 & 1.2 & 0.6 & 0.8 & 0.5 & 0.9 \\
\hline $99 \%$ CI & 4.6 & 3.8 & 3.5 & 3.5 & 5.1 & 4.2 & 3.6 & 3.4 \\
\hline Outer range & 6.0 & 4.5 & 4.0 & 4.0 & 5.1 & 4.5 & 3.8 & 3.5 \\
\hline \multicolumn{9}{|l|}{ Female } \\
\hline Mean & 3.2 & 2.8 & 2.5 & 2.3 & 3.8 & 3.4 & 2.8 & 2.2 \\
\hline SD & 0.8 & 1.1 & 0.8 & 0.4 & 1.1 & 1.0 & 1.3 & 1.1 \\
\hline $99 \%$ CI & 3.8 & 3.7 & 3.1 & 2.6 & 4.7 & 4.1 & 3.8 & 3.1 \\
\hline Outer range & 4.5 & 4.5 & 3.7 & 3.0 & 5.5 & 5.0 & 4.5 & 4.0 \\
\hline
\end{tabular}

All distances are in centimeters and reflect the distance measured transversely from the anterior scapular border to the LTN. Measurements were made at the scapular "tip" and at 2-cm intervals along the anterior scapular border cephalad from the scapular tip. SD, Standard deviation; $99 \% C I$, upper bound of the $99 \%$ confidence interval for the mean; outer range, outer value of the range of measurements.

result of LTN injury. Before the proliferation of open thoracotomy techniques, most LTN injury resulted from nerve pinching between the coracoid process and the first or second rib as the result of patient positioning (especially while anesthetized), trauma, or lifting heavy objects. ${ }^{5-7}$ Many of these cases of winged scapula resolved with shoulder immobilization followed by physical therapy. In contrast, current studies indicate that LTN injury results in both significant and chronic disability. Kauppila and Vastamaki ${ }^{1}$ followed the longterm outcome in 26 patients with iatrogenic LTN injury. Despite extensive therapy, all but one patient had residual long-term symptoms. Long-term disability included loss of ability to pull or lift objects in $81 \%$ of patients, inability to play sports in $58 \%$ of patients, and failure to work with their hands above shoulder level in $54 \%$ of patients. It is the chronic nature of LTN-injury disability along with its adverse impact on quality of life and work that leads some patients to subject the events leading to LTN injury to legal review.

LTN injury has been reported after radiotherapy, ${ }^{8}$ trauma, patient positioning, ${ }^{5-7}$ transaxillary breast augmentation, ${ }^{9}$ implantation of transvenous leads, ${ }^{10}$ anesthetic nerve blocks, and transaxillary incisions. ${ }^{1,4}$ Whereas the disability associated with winged scapula is well documented, the exact incidence is not. Kauppila and Vastamaki, ${ }^{1}$ in a review of 197 cases, found an iatrogenic cause of LTN injury in 16\% of the cases. Surgical and anesthetic injuries accounted for $69 \%$ and $31 \%$ of cases, respectively, in their series. Whereas large series of transaxillary incisions have been reported without LTN injury, ${ }^{11-13}$ Wood and 

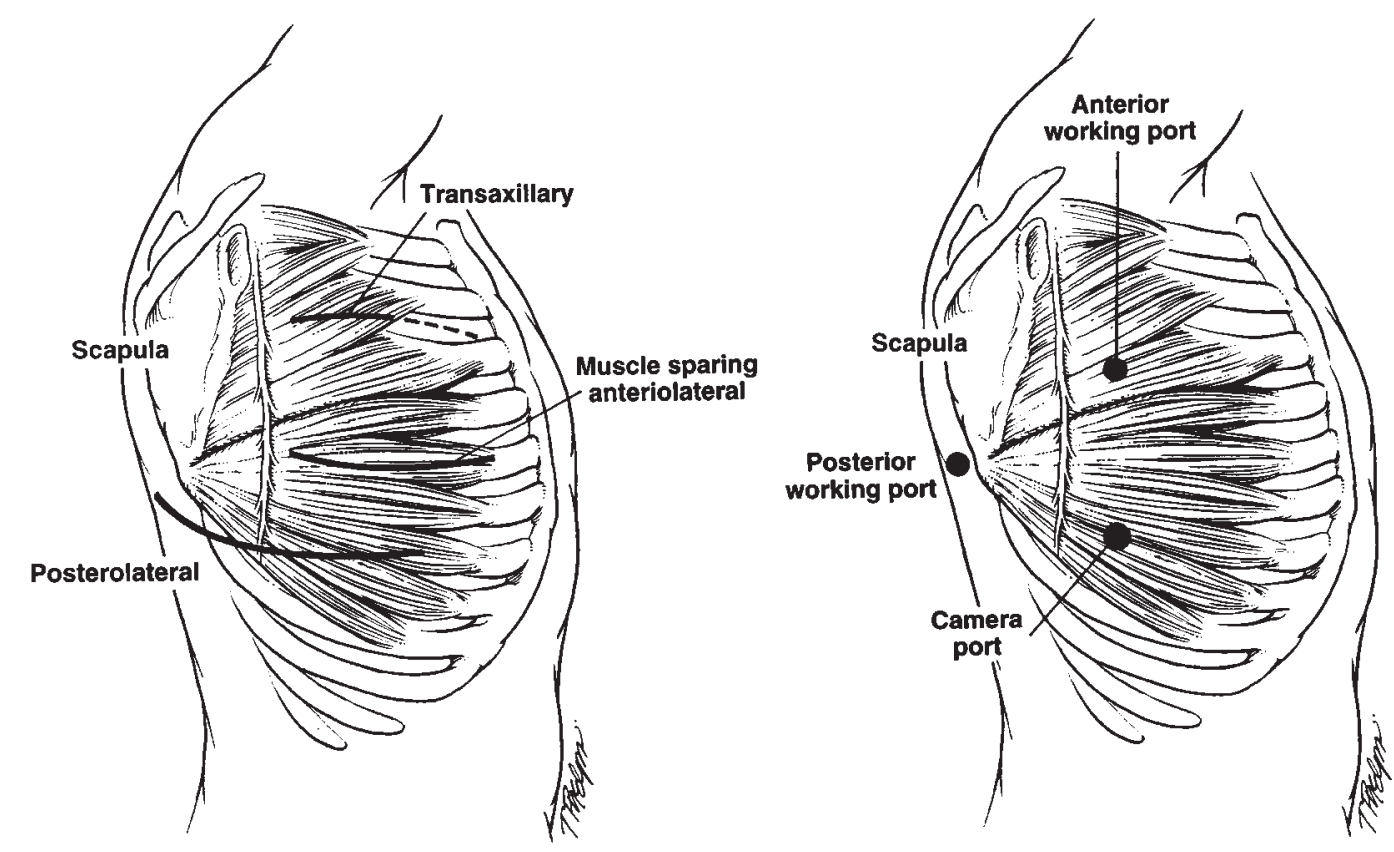

Fig 3. The relationship of transaxillary, anterolateral muscle sparing, posterolateral incisions, and thoracoscopy port incisions is shown in $\mathbf{A}$ and $\mathbf{B}$, respectively. Extension of transaxillary incisions anteriorly avoids proximal LTN injury.

Frykman ${ }^{4}$ found LTN injury to be the second most common complication of first rib resection after pneumothorax. In their series it accounted for $12.5 \%$ of postoperative complications. Bardy and associates ${ }^{10}$ had one transient LTN paralysis (2.4\%) after insertion of transvenous cardioverter-defibrillators. Standard posterolateral thoracotomy incisions divide the serratus muscle low enough that the lower serratus unit is still functionally intact and the scapular tip remains stabilized. Incisional techniques that spare the serratus anterior muscle also protect the LTN. Iatrogenic LTN injury is not common but undoubtedly occurs more commonly than is reported.

Thoracic surgeons now have a wide range of incisional options to choose from, including standard and musclesparing thoracotomies, thoracoscopy, video-assisted thoracic surgerical techniques, and minithoracotomies (such as the transaxillary incision). Thoracotomy incisions cephalad to the scapular tip, including port sites, are at risk for iatrogenic proximal LTN injury and winged scapula. The objective of this study was to develop clinically applicable guidelines to aid in the prevention of iatrogenic proximal LTN injuries. By mapping the course of the LTN relative to the scapula, the landmark most commonly used to orient standard thoracotomy incisions, we believe that we have developed a quick and clinically useful method to minimize the risk of LTN injury.
The LTN is a branch of the cervical plexus emanating from cervical roots. ${ }^{5-7}$ The nerve passes behind the brachial plexus to enter the axilla where it then courses inferiorly onto the surface of the serratus anterior muscle. ${ }^{14,15}$ The serratus anterior muscle has fleshy muscle slips originating from the upper 8 or 9 ribs anteriorly and inserting along the entire medial aspect of the scapula posteriorly. The muscular portion from ribs 1 to 3 form a less cohesive muscular unit that inserts diffusely along the medial aspect of the upper scapula. However, the muscular slips originating from ribs 4 to 9 converge posteriorly as a tendon that inserts onto the scapular tip (Fig 2). The serratus anterior muscle is therefore anatomically divided into 2 components, an upper part in which the muscular slips function individually and a lower part that functions as a cohesive unit to stabilize the scapular tip. The LTN sparsely innervates the upper serratus through small branches and then arborizes more extensively to innervate the lower serratus. There is no change in nerve location as a function of body, arm, or shoulder position. We found remarkable consistency in nerve anatomy in the 34 (17 bilateral) dissections performed, a finding confirmed by others. ${ }^{15}$

We have defined proximal LTN injuries as those occurring cephalad to the scapular tip. We believe that there is anatomic justification for doing so. Intact function of the lower serratus muscular unit is essential for 
scapular stabilization. Division of the LTN inferior to the scapular tip, as with a standard posterolateral thoracotomy incision, preserves most of the innervation to the lower serratus anterior muscle unit, which stabilizes the scapular tip. However, division of the LTN cephalad to the scapular tip denervates the entire lower serratus muscular unit, destabilizing or "winging" the scapula.

Our data show that the LTN is located the greatest distance from the scapula at its tip. Then, because the nerve courses vertically, the nerve gets progressively closer to the anterior scapular border. The relationship of nerve and scapula forms a triangular-shaped region within which the proximal nerve is situated, and therefore at risk for injury (Fig 1, shaded area). The size of this trianglar region varies with arm positioning. With the arm flexed forward as with a standard posterolateral thoracotomy, the scapula moves anteriorly closer to the nerve, position of which remains unchanged. As the arm is extended posteriorly as with transaxillary positioning, the scapula moves further from the nerve, exposing more of the nerve for potential injury. In the transaxillary thoracotomy position, the left LTN was $4.9 \mathrm{~cm}$ (range, 3.2-7.0 $\mathrm{cm}$ ) and $4.3 \mathrm{~cm}$ (range, 3.0-5.0 $\mathrm{cm}$ ) from the scapular tip for male and female subjects, respectively. The right LTN was $5.2 \mathrm{~cm}$ (range, 3.7-7.5 $\mathrm{cm}$ ) and $4.7 \mathrm{~cm}$ (range, 3.0-6.0 $\mathrm{cm}$ ) from the scapular tip for male and female subjects, respectively. As expected, for posterolateral thoracotomy positioning, the nerve was closer to the scapula. The left LTN was $3.1 \mathrm{~cm}$ (range, $1.5-6.0 \mathrm{~cm}$ ) and $3.2 \mathrm{~cm}$ (range, 2.0-4.5 $\mathrm{cm}$ ) from the scapular tip for male and female subjects, respectively. The right LTN was $4.5 \mathrm{~cm}$ (range, 3.5-5.1 $\mathrm{cm}$ ) and $3.8 \mathrm{~cm}$ (range, $2.0-5.5 \mathrm{~cm}$ ) from the scapular tip for male and female subjects, respectively. There were no statistically significant differences in our measurements by gender or side. The difference in observed distance from the scapular tip to the LTN between right and left sides may be related to handedness, but this information was not available for this study.

The relationship of the transaxillary, anterolateral muscle sparing, posterolateral thoracotomy incisions, and thoracoscopy port sites to the LTN is shown in Fig 3. Incisions cephalad to the scapular tip should be extended anteriorly if additional exposure in needed to avoid LTN nerve injury. Posterolateral incisions divide the serratus muscle below the scapular tip, which maintains sufficient innervation of the lower serratus unit to maintain scapular stability.
On the basis of our data, we suggest the following clinical guidelines for incisions anterior and cephalad to the scapular tip. We have purposely selected the outer range distances (Tables I and II), as opposed to mean or $99 \%$ CI values, to be as conservative as possible in our recommendations. For patients in the transaxillary thoracotomy position, incisions should be a distance of at least $7.5 \mathrm{~cm}$ and $6.0 \mathrm{~cm}$ anterior to the scapular tip for male and female patients, respectively. For patients in standard posterolateral thoracotomy positioning, incisions should be at least $6.0 \mathrm{~cm}$ and 5.5 $\mathrm{cm}$ anterior to the scapular tip for male and female patients, respectively. The use of these guidelines in our clinical practice has not resulted in any limitations to surgical exposure. We believe that the incidence of iatrogenic proximal LTN injury can be minimized by using these guidelines to position incisions in the anterior scapular region.

\section{REFERENCES}

1. Kauppila LI, Vastamaki M. Iatrogenic serratus anterior paralysis: long-term outcome in 26 patients. Chest 1996;109:31-4.

2. Goodman CE, Kenrick MM, Blum MV. Long thoracic nerve palsy: a follow-up study. Arch Phys Med Rehabil 1975;56:352-8.

3. Heitmiller RF. Thoracic incisions. In: Baue AE, Geha AS, Hammond GL, Laks H, Naunheim KS, editors. Glenn's thoracic and cardiovascular surgery. 6th ed. Stamford [CT]: Appleton \& Lange; 1996. p. 73-89.

4. Wood VE, Frykman GK. Winging of the scapula as a complication of first rib resection: a report of six cases. Clin Orthop 1980; 149:160-3.

5. Prescott MU, Zollinger RW. Alar scapula: an unusual surgical complication. Am J Surg 1944;65:98-103.

6. Horwitz MT, Tocantins LM. Isolated paralysis of the serratus anterior (muscle) muscle. J Bone Joint Surg Am 1938;20:720-5.

7. Thorek M. Compression paralysis of the long thoracic nerve following an abdominal operation. Am J Surg 1926;40:26-7.

8. Pugliese GN, Green RF, Antonacci A. Radiation-induced long thoracic nerve palsy. Cancer 1987;60:1247-8.

9. Laban E, Kon M. Lesion of the long thoracic nerve during transaxillary breast augmentation: an unusual complication. Ann Plast Surg 1990;24:445-6.

10. Bardy GH, Hofer B, Johnson G, et al. Implantable transvenous cardioverter-defibrillators. Circulation 1993;87:1152-68.

11. Roos DB. Experience with first rib resection for thoracic outlet syndrome. Ann Surg 1971;173:429-42.

12. Urschel HC, Paulson DL, McNamara JJ. Thoracic outlet syndrome. Ann Thorac Surg 1968;6:1-10.

13. Rainer WG, Vigor W, Newby JP. Surgical treatment of thoracic outlet compression. Am J Surg 1968;116:704-7.

14. Hollingshead WH, Rosse C. Textbook of anatomy. 4th ed. Philadelphia: Harper and Row; 1985. p. 179-97.

15. Cuadros CL, Driscoll CL, Rothkopf DM. The anatomy of the lower serratus anterior muscle: a fresh cadaver study. Plast Reconstr Surg 1995;95:93-7. 